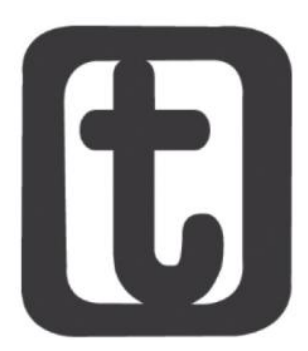

\title{
FORMAÇÃO POR COMPETÊNCIA NO SERVIÇO SOCIAL: NOVAS EXIGÊNCIAS DO MERCADO DE TRABALHO
}

\author{
Competence training in social work: new labor market requirements
}

Mayra de Queiroz*

https://orcid.org/0000-0002-2240-7587

\section{RESUMO}

O presente texto versa sobre a formação por competência no Serviço Social sob as influências dos organismos internacionais como uma das novas exigências do mercado de trabalho. Nosso objetivo é trazer à discussão o conceito de competência para o mercado e como este influencia as determinações da formação profissional no século XXI. As recomendações dos organismos internacionais para uma competência adequada ao mercado evidenciam uma adequação da Educação com parâmetros que burocratizam os serviços. É com base nos princípios norteadores das Diretrizes Curriculares para o curso de Serviço Social e nas defesas de alguns autores da área que iremos contrapor o conceito de competência para o mercado de trabalho. $O$ debate respaldado pelos autores do Serviço Social levanta reflexões sobre a possibilidade de uma competência que ultrapasse a valorização do mercado e que garanta uma leitura crítica do real.

\section{PALAVRAS-CHAVE}

Educação Superior. Serviço Social. Competência.

\begin{abstract}
This text deals with training by competence in Social Work under the influence of international organizations as one of the new demands of the labor market. Our objective is to bring to the discussion the concept of competence for the market and how it influences the determinations of professional training in the 21st century. The recommendations of international organizations for an adequate competence for the market show an adequacy of Education with parameters that bureaucratize services. It is based on the guiding principles of the Curricular Guidelines for the Social Work course and the defenses of some authors in the area that we will oppose the concept of competence for the job market. The debate supported by the authors of Social Work raises reflections on the possibility of a competence that exceeds the appreciation of the market and that guarantees a critical reading of the real.
\end{abstract}

\section{KEYWORDS}

College education. Social Work. Competence.

Submetido em: 21/04/2020.

Aceito em: 27/10/2020.

\begin{abstract}
* Assistente Social. Mestra em Serviço Social. Docente do curso de Serviço Social da Universidade Federal de Alagoas. (UFAL, Palmeira dos Índios, Brasil). R. Sonho Verde, s/n, Eucalipto, Palmeira dos Índios (AL), CEP.: 57606-100. E-mail: mayra_queiroz.b@hotmail.com.
\end{abstract}

DOI 10.22422/temporalis.2020v2on40p47-63

\section{(cc) $\mathrm{BY}$}

๑ A(s) Autora(s)/O(s) Autor(es). 2019 Acesso Aberto Esta obra está licenciada sob os termos da Licença Creative Commons Atribuição 4.0 Internacional (https://creativecommons.org/licenses/by/4.o/deed.pt_BR), que permite copiar e redistribuir o material em qualquer suporte ou formato, bem como adaptar, transformar e criar a partir deste material para qualquer fim, mesmo que comercial. O licenciante não pode revogar estes direitos desde que você respeite os termos da licença. 


\section{temPOCOliS Queroz, MavraAE}

\section{INTRODUÇÃO}

Q uando falamos em competência remetemos à ideia de um sujeito que possui o domínio de conhecimentos, habilidades, destreza para fazer algo. Na sociedade burguesa a competência é expressa nas metas e objetivos alcançados com a burocratização dos serviços e ações pelos quais os sujeitos estejam envolvidos. Todavia, a forma como se burocratizam os serviços e ações impulsionam uma série de antagonismos que vão desde o velamento das reais necessidades do capitalismo até às formas mais imediatas em responder às necessidades dos homens para mantê-los sob controle. Neste sentido, o discurso competente expressa uma capacidade em responder ao efêmero, ao não dito, com base numa neutralidade racional que oculta o real.

Com base na análise crítica sobre o capitalismo, a competência está para além do manejo em fazer com destreza através do domínio de conhecimentos. A palavra competência tem origem no termo latim competere que significa aptidão para cumprir alguma tarefa ou função. Por esse entendimento, em grande medida essa compreensão indica um atributo de decidir sobre determinada causa, de modo que resolva uma situaçãoproblema. Quando somada ao termo profissional, essa indica uma aptidão, conhecimento ou capacidade em alguma área específica.

Não por acaso, o uso do conceito de competência tem sido utilizado no campo da educação, expondo o debate entre qualificação e formação por competência, que se estabeleceu por volta dos anos de 1980 enquanto efeito das exigências do mundo do trabalho. Essas discussões têm sido fundamentadas pelas elaborações da sociologia do trabalho e apropriada pelos organismos internacionais, tais como: Organização das Nações Unidas para a Educação, a Ciência e a Cultura (UNESCO) e a União Europeia, na defesa do redimensionamento da qualificação a partir de um modelo por competência que vise responder a um perfil de profissional previamente estabelecido pelo mercado de trabalho.

Nesse sentido, nosso estudo objetiva, ainda que brevemente, trazer as propostas postas pela formação por competência a partir das ideias de Phillipe Zarifan (2001, 2003) e de documentos dos organismos internacionais, bem como demonstrar como essa proposta tem implicação nos documentos legitimadores da formação profissional em Serviço Social, a exemplo das Diretrizes Curriculares para o curso de Serviço Social. Para tanto, traremos alguns contrapontos e defesas de autores, que debruçam suas pesquisas sobre os Fundamentos do Serviço Social, acerca da competência, a saber: lamamoto (2009, 2012, 2014, 2017), lamamoto e Carvalho (2007), Guerra (2007, 2016, 2017) e Trindade (2001, 2017).

Apesar do termo competência ser usual pela categoria profissional, aqui englobamos profissionais inseridos no campo e nos espaços acadêmicos. No entanto, é parco o acervo bibliográfico acerca de sua compreensão. Essa questão demonstra a necessidade de discutirmos o presente objeto em uma conjuntura de reformas no Ensino Superior e de incorporação dos delineamentos da formação por competência nas Diretrizes Curriculares dos cursos de Ensino Superior no Brasil. Torna-se necessário lançarmos os 
olhos para buscar resposta a algumas questões: a que lógica responde a formação por competência? em que sentido a concepção de competência profissional posta pelo projeto de formação profissional em Serviço Social diverge da concepção apresentada por intuições como o Ministério da Educação (MEC)? Afinal, a partir de quais elementos podemos indicar a compreensão de competência no Serviço Social? Sabemos que as respostas a essas indagações exigem uma análise acurada e que, portanto, requer os contínuos debates, estudos e pesquisas acerca dos fundamentos do Serviço Social.

\section{FORMAÇÃO POR COMPETÊNCIA NO ENSINO SUPERIOR: LIAMES ENTRE EDUCAÇÃO E MERCADO DE TRABALHO}

As discussões acerca da formação ou modelo por competência no Ensino Superior ganhou espaço a partir dos anos de 1990. Com a eclosão da crise estrutural do capital, nos meados dos anos de 1970, assistiu-se a um processo de reestruturação produtiva, o qual exigiu de representantes do capital respostas no intuito de tentar recompor seu ciclo de lucro. Nesse cenário, a educação foi posta como nicho estratégico no atendimento aos interesses do capital. Parte das estratégias é postulada na adesão ao modelo toyotista de produção e do neoliberalismo, em que o Estado se encarregou de aplicar fielmente os princípios neoliberais. Foi, portanto, nesse cenário que se tornou questionável a qualificação do trabalhador face às novas exigências postas pelo mundo do trabalho, enquanto que no modelo de produção taylorista-fordista a aquisição de diplomas e certificados remetia-se à determinada ocupação, isto é, o modelo fordista caracterizado pela produção rígida demandou um trabalhador com características para ocupar determinado posto de trabalho. Nesse sentido, há uma defesa da qualificação para o posto de trabalho (ZARIFIAN, 2001; RAMOS, 2002; MACHADO, 2002).

Ao contrário dessa postura, com o modelo flexível toyotista ocorreu um redimensionamento do conceito de qualificação que trouxe implicações aos parâmetros de formação profissional de "[...] acesso ao emprego, de classificação e de remuneração [...]" (RAMOS, 2002, p. 402) a partir das características do modelo flexível, a saber: trabalhador polivalente, multifuncional, flexível, se pôs a necessidade de apropriação do conteúdo intelectual do trabalhador a serviço dos interesses do capital. Nesse cenário, são apropriados pelo capital os saberes, as habilidades, as qualidades do trabalhador. Nessas condições, os trabalhadores se veem obrigados a buscarem por capacitações e especializações que possibilitem o seu desenvolvimento face ao novo modelo de produção moderno e flexível. Para tanto, fomenta-se o discurso de profissional competente, do saber agir, deslocando para a esfera da subjetividade do trabalhador o sucesso ou insucesso do processo de produção. Para alguns autores, haveria uma nova noção de qualificação baseada no modelo por competência, adaptando-se ao modelo de produção flexível e estendendo-o a diversas áreas do conhecimento. Nesse sentido, Ramos (2002) denota haver "[...] um movimento generalizado em diversos países do mundo, de reformulação de seus sistemas de educação” (RAMOS, 2002, p. 402).

Posto isso, em meados da década de 1980, marcada pelas referidas mudanças no mundo do trabalho e pela captura da subjetividade do indivíduo, surgiu a noção de competência vinculada à organização e produção da empresa flexível. Enquanto precursor da noção 


\section{tempordils

científica de competência destaca-se o pesquisador francês Philippe Zarifian, o qual dedicou sua pesquisa no âmbito da sociologia do trabalho francesa, na análise da relação entre competência, trabalho e organização, constituindo sua tese central a partir do modelo de competência enquanto modelo de gestão de recursos humanos. Segundo Werner (2010), para Zarifian:

\footnotetext{
Competência é a inteligência prática para situações que se apoiam sobre os conhecimentos adquiridos e os transformam com tanto mais eficácia, quanto mais aumenta a complexidade das situações - só se manifesta através de ações na atividade prática (WERNER, 2010, p. 39).
}

Em sua obra o autor assevera a necessidade de superar a oposição entre qualificação e competência, propondo a ideia de abordagem da competência associada à qualificação, ainda que não possam ser tomadas de modo complementares. A referida defesa assentase na proposição do deslocamento da compreensão de "[...] qualificação do emprego [...]" para a "[...] qualificação do indivíduo" (ZARIFIAN, 2001, p. 18). É conservada a compreensão de qualificação, mas agora trazendo para o âmbito da subjetividade, da responsabilidade de acúmulo de conhecimento adquirido pelos indivíduos, ao contrário dos conhecimentos adquiridos pelo emprego.

Essas concepções acabam por responsabilizar os indivíduos por sua qualificação e inserção no mercado de trabalho a partir do discurso de qualificação/competência/empregabilidade, desconsiderando os determinantes da crise do capital e do desemprego estrutural ${ }^{1}$. Assim, o discurso assenta-se na ideia de que quanto mais qualificado e competente profissionalmente aumentam-se as chances de inserção do mercado competitivo de trabalho. Não iremos aprofundar as causas do desemprego estrutural visto que não é nosso objeto de estudo, mas a noção de competência está imbricada nesse sentido: naturaliza-se o desemprego e ainda coloca nos sistemas educacionais a centralidade para resolução das contradições da ordem do capital.

Nessa direção, os representantes financeiros do capital dispuseram de estratégias para repensar a formação de trabalhadores de diversas áreas de conhecimento a serviço das novas mudanças no mundo do trabalho, repensando os currículos e as competências requisitadas pelo mercado. Consequentemente, a qualificação via formação superior torna-se esfera de lucro para o capital, assim, põe-se como necessária a institucionalização da formação por competências via: documentos, declarações, legislações proferidas pelos organismos e instituições internacionais e nacionais, os quais gestaram as bases das reformas nos sistemas educacionais.

Notadamente, nos anos de 1990, tais questões tornaram-se atrativas à Organização das Nações Unidas para a Educação, a Ciência e a Cultura (UNESCO), além de exportadores educacionais como a União Europeia, os quais propuseram reformar aos sistemas educacionais de cada país, sejam centrais ou periféricos, no sentido de responder às necessidades mercadológicas, inferindo modificações nos currículos e o ensino nas áreas

${ }^{1}$ MÉSZÁROS (2002). 
do conhecimento. Assim, conforme Bruno (2011), os ajustes nos sistemas educacionais podem ser verificados na esfera da racionalização da gestão administrativa, financeira e pedagógica das instituições formadoras, baseadas em critérios de eficácia, excelência e produtividade, inseridos nas diversas áreas. As recomendações dessas instituições colocam a adequação da educação às exigências do desenvolvimento flexível. Para isso, na década de 1990 foi elaborado um manancial de documentos que gestou uma nova proposta de Ensino Superior, centrada no ensino por competências.

O modelo por competência a partir da educação é assumido pela UNESCO em seus diversos documentos. A organização delibera a necessidade a aprendizagem dos indivíduos ao longo da vida e do desenvolvimento de competências. Segundo o Relatório Educação: um tesouro a descobrir, o qual ficou conhecido como Jacques Delors, elaborado pela Comissão Internacional sobre a educação para o século XXI, a educação deverá se organizar em quatro aprendizagens:

\begin{abstract}
Aprendizagens fundamentais que, ao longo de toda a vida, serão de algum modo para cada individuo, os pilares do conhecimento: aprender a conhecer, isto é adquirir os instrumentos da compreensão; aprender a fazer, para poder agir sobre o meio envolvente; aprender a viver juntos, a fim de participar e cooperar com os outros em todas as atividades humanas; finalmente aprender a ser, via especial que integra as três precedentes. É claro que estas quatro vias do saber constituem apenas uma, dado que existem entre elas múltiplos pontos de contato, de relacionamento e de permuta (DELORS, 1998, p. 90).
\end{abstract}

A educação, com base nos referidos quatro pilares, pontua reformular os sistemas educacionais, seus objetivos, conteúdos, com vista ao desenvolvimento dos estudantes para as exigências atuais do mercado. Observa-se o fortalecimento da relação: formação de capital humano, por via da educação superior, e as requisições mercadológicas, a partir da defesa do desenvolvimento dos países latinos. Interessante destacarmos a Declaração Mundial sobre Educação Superior para o século XXI: visão e ação da UNESCO, resultado da Conferência Mundial sobre Educação Superior para o século XXI: visão e ação, realizada em Paris, no ano de 1998. Em seu artigo $7^{\circ}$, acerca da cooperação entre mundo do trabalho e educação superior, a declaração destaca que a educação deve responder às novas exigências do mundo do trabalho, desenvolvendo e avaliando conjuntamente os processos de aprendizagem, programas de transição, avaliação e validação de conhecimentos prévios que integrem a teoria e a formação no próprio trabalho, além de estimular o desenvolvimento das habilidades empresariais e o senso de iniciativa dos formandos, no sentido dos estudantes desenvolverem suas próprias habilidades com um senso de responsabilidade social.

A reestruturação da formação por competência pode também ser encontrada nas propostas da União Europeia com o projeto Tuning Educational Structures in Europe, iniciado na Europa, em 1999, e que partiu dos objetivos do Espaço Europeu de Educação Superior (EEES), desenvolvidos segundo os critérios do Processo de Bolonha. O Projeto situa as competências em dois ciclos na graduação e na pós-graduação (incluindo mestrado e doutorado), com foco na aprendizagem individual, no estímulo ao desenvolvimento de capacidades, habilidades e destrezas e na organização das disciplinas 


\section{temporalis

necessárias ao desenvolvimento de competências que são estruturadas para um perfil de profissional estabelecido previamente. Os objetivos educativos estabelecidos para cada ciclo devem ser diferenciados, centrado nos procedimentos e não no conteúdo. Segundo Bolívar (2009), o ciclo inicial - graduação - deve ter uma orientação para a profissionalização; e o segundo - pós-graduação - para a especialização. A nosso ver, essa nova roupagem da formação por competência centrada em procedimento e não no conteúdo, acaba por deslocar a centralidade do conhecimento de caráter teórico para conteúdos de caráter meramente instrumentalizável, além de incorporar destrezas e capacidades próprias dos indivíduos como centrais, em conformidade com as defesas de Zarifian (2001).

Com a expansão do Projeto Tuning, a América Latina foi incluída nesse processo de reestruturação dos sistemas de ensino, sendo desenvolvida a partir do Projeto Alfa Tuning América Latina, 2003, entre os países incorporados - o Brasil, que tem como objetivo contribuir com o desenvolvimento de titulações “[...] facilmente comparáveis e compreensíveis, de uma forma articulada em toda América Latina, buscando pontos de referência comuns e centrando-se nas competências e destrezas [...]" (BOLÍVAR, 2009, p. 104) em relação ao perfil de profissional que se deseja obter para o mercado. De acordo com o Relatório final do Projeto Tuning, na América Latina são enfatizadas quatro linhas de trabalho, a saber: 1. Competências (gerais e específicas das áreas temáticas); 2. Enfoque de ensino, aprendizado e avaliação destas competências; 3. Créditos acadêmicos; e 4. Qualidade dos programas (TUNING AMÉRICA LATINA, 2007).

Debrucemo-nos na análise da primeira linha, foco da nossa discussão. Segundo Bolívar, as competências gerais são transferíveis e comuns para qualquer titulação, subdivididas em competências instrumentais, interpessoais e sistemáticas. As competências específicas estão ligadas às áreas de estudo (conhecimento teórico, prático e/ou experimental e habilidades específicas da área) (BOLÍVAR, 2009). Logo, as competências gerais englobam capacidades integrais, a saber: comunicação, capacidade de síntese, colaboração, liderança, dentre outras que podem ser desenvolvidas e utilizadas em diferentes situações e áreas do conhecimento. Por outro lado, as competências específicas estão atreladas às áreas de estudo e habilidades de uma dada formação, concebidas por meio de programas de formação de educação superior ou formação profissional. Isso significa dizer que cada curso definirá com o conjunto da profissão quais as competências gerais e específicas fundamentam a atividade profissional. Retornaremos a essa questão no próximo item, quando discutiremos as competências profissionais em Serviço Social.

Em suma, o modelo de educação superior gestado pela formação por competência influenciou, portanto, os sistemas educacionais na América Latina, e no caso brasileiro esse cenário não se constitui diferente. O Brasil redimensionou seu sistema educacional a partir da entrada dos anos de 1990, incorporando o discurso por competências em diversos cursos de graduação e pós-graduação, a partir de legislações, medidas provisórias, resoluções do MEC, do Conselho Nacional de Educação (CNE) e da Secretaria de Educação Superior (SESu). Vejamos como essas tendências exercem influências nos documentos que regulam a formação de profissões como a do/a assistente social na 


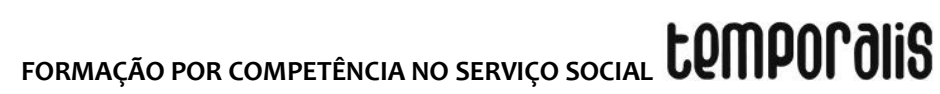

tentativa de redimensionar a compreensão de competência profissional aliada ao mercado.

\section{COMPETÊNCIA PROFISSIONAL NO SERVIÇO SOCIAL: EMBATES ENTRE AS DEFESAS DA PROFISSÃO E A LÓGICA MERCADOLÓGICA}

As propostas de redirecionamento da educação superior brasileira a partir do modelo por competência foram consagradas pelo governo de Fernando Henrique Cardoso, durante a década de 1990. Podemos encontrar orientações desse modelo a partir da Lei de Diretrizes e Bases da Educação Nacional (LDB), Lei $n^{\circ}$ 9.394/96 (BRASIL, 1996) e de legislações como pareceres e editais, os quais puseram na agenda do ensino superior delineamentos para a formação de um perfil de profissional apto às exigências mercadológicas. Esses direcionamentos não têm se mostrado diferentes no curso de Serviço Social. A LDB traz a flexibilidade e a avaliação como eixos articuladores da proposta para o Ensino Superior.

Ainda no ano de 1996, foi aprovada as Diretrizes Curriculares para o Curso de Serviço Social pela Associação Brasileira de Ensino em Serviço Social (ABESS)², revisadas em 1999, apresentando ao MEC/CNE a proposta de currículo mínimo para o Curso de Serviço Social. As Diretrizes são fruto de debates da categoria, apontam os pressupostos para formação profissional em Serviço Social, travejado pelos princípios norteadores da profissão, destacamos alguns: flexibilidade de organização dos currículos plenos; rigoroso trato teórico, histórico e metodológico da realidade social e do Serviço Social; adoção de uma teoria social crítica que possibilite a apreensão da totalidade social; superação da fragmentação de conteúdos na organização curricular; estabelecimento das dimensões investigativa e interventiva como princípios formativos, dentre outros (ABEPSS/CEDEPSS, 1997).

Entretanto, a proposta do currículo mínimo foi revista no ano seguinte a partir do Parecer $n^{\circ}$ 776/97 (BRASIL, 1997a) elaborado pelo Conselho Nacional de Educação, que orienta sobre as diretrizes curriculares dos cursos de graduação, propondo que as diretrizes curriculares assegurem a flexibilidade e a qualidade na formação, mediante os seguintes princípios: ampla liberdade na composição de estudos a serem ministrados, redução da carga horária dos cursos, incentivo à sólida formação geral, práticas de estudos independentes, articulação teoria-prática e avaliações periódicas com instrumentos variados. No que diz respeito às competências e habilidades, o Parecer propõe encorajar o reconhecimento de conhecimentos, habilidades e competências adquiridas fora do ambiente escolar, inclusive as que se referirem à experiência profissional julgada relevante (BRASIL,1997a).

Elaboradas as propostas a partir do Parecer $n^{\circ} 776 / 97$, no mesmo ano, o Ministério de Educação e do Desporto, mediante a Secretaria de Educação Superior (SESu), tornou público o Edital $n^{\circ}$ 04/97, convocando as instituições de ensino superior a apresentarem

\footnotetext{
2 A ABESS (Associação Brasileira de Escolas de Serviço Social) e o CEDEPSS (Centro Brasileiro de Documentação e Pesquisa sobre Políticas Sociais e Serviço Social) foram incorporados em 1998 a uma só entidade, a ABEPSS (Associação Brasileira de Ensino e Pesquisa em Serviço Social).
} 


\section{tempordils

propostas para as novas Diretrizes Curriculares dos cursos superiores, as quais foram elaboradas pelas comissões de especialistas. O referido edital orienta no sentido da organização das Diretrizes Curriculares dos Cursos, destacando orientações básicas como: perfil desejado do formado; competências e habilidades desejadas; conteúdos curriculares; duração dos cursos, estruturação modular dos cursos; estágios e atividades complementares; conexão com a avaliação institucional. Notadamente, o edital visa conferir às Diretrizes Curriculares do Curso um caráter de flexibilidade concernente com o desenvolvimento econômico flexível. Além disso, sugere uma reorganização dos conteúdos disciplinares com vista à formação de um perfil de profissional estabelecido previamente pelas exigências mercadológicas, como salientamos no item anterior.

Segundo Werner (2010), as modificações pontuadas demonstram a centralidade da flexibilidade nos processos de elaboração curricular, verificadas na substituição dos conteúdos mínimos e grades curriculares para a elaboração de Diretrizes Curriculares. Ainda para a autora, é nesse cenário que se intensifique a formação baseada em competências e habilidades, inseridas e construídas ao longo dos cursos, nos trabalhos desenvolvidos nos conteúdos disciplinares, na relação teoria e prática, nos estágios. Assim, esses elementos deverão ser atendidos em todo o projeto pedagógico de cada curso de ensino superior.

No sentido de substanciar as propostas postas na década de 1990, em 2001 foi aprovado pelo Conselho Nacional de Educação/Câmara Superior de Educação - CNE/CSE os Pareceres $n^{\circ}$ 492/2001 (BRASIL, 2001a) e 583/2001 (BRASIL, 2001b), aprovados respectivamente nos dias 03 e 04 de abril de 2001. Com relação a este último, o Parecer reafirma as orientações já preconizadas no Parecer $n^{\circ}$ 776/97 (BRASIL, 1997a) e no Edital $n^{\circ}$ 4/97 (BRASIL, 1997b). O Parecer n 492/2001 (BRASIL, 2001a) trata acerca das Diretrizes Curriculares Nacionais dos cursos de Filosofia, História, Geografia, Serviço Social, Comunicação Social, Ciências Sociais, Letras, Biblioteconomia, Arquivologia e Museologia. Neste são apresentadas as orientações para os eixos: perfil dos Formandos, competências e habilidades (gerais e especificas), organização do curso, conteúdos curriculares, estágio supervisionado e trabalho de conclusão de curso (TCC), atividades complementares. Eixos atendidos na Resolução CNE/CES 15/2002 (BRASIL, 2002), que estabelece as Diretrizes Curriculares para os cursos de Serviço Social.

Ao analisarmos o Parecer $n^{\circ}$ 492/2001 (BRASIL, 2001a), verificamos haver modificações significativas concernentes à proposta do texto original das Diretrizes Curriculares para o Curso de Serviço Social propostas e aprovadas pela ABEPSS em 1997. No texto original consta que as competências e atribuições profissionais devem recorrer a uma formação mediante a capacitação:

[...] Teórico-metodológica, ético-política e técnico-operativa para a: 1. Apreensão crítica do processo histórico como totalidade; 2 . Investigação sobre a formação histórica e os processos sociais contemporâneos que conformam a sociedade brasileira, no sentido de apreender as particularidades da constituição e desenvolvimento do capitalismo e do Serviço Social no país; 3. Apreensão do significado social da profissão (ABEPSS, 1997, p. 7). 


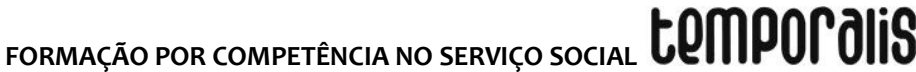

Com o Parecer $n^{\circ}$ 492/2001 (BRASIL, 2001a), o MEC dividiu as competências em gerais e específicas, em conformidade com o Projeto Tuning América Latina. Nas gerais foi excluída toda a passagem anteriormente mencionada que iniciava o texto abaixo, restando apenas o seguinte trecho:

A formação profissional deve viabilizar uma capacitação teórico-metodológica e ético-política, como requisito fundamental para o exercício de atividades técnico-operativas, com vistas à compreensão do significado social da profissão e de seu desenvolvimento sócio-histórico, nos cenários internacional e nacional, desvelando as possibilidades de ação contidas na realidade; identificação das demandas presentes na sociedade, visando a formular respostas profissionais para o enfrentamento da questão social (BRASIL, 2001a, p. 401-402).

As formulações acima constam nas Diretrizes Curriculares para o curso de Serviço Social/MEC/2002 construído a partir do mencionado parecer. No que se refere às competências específicas, o documento dispõe:

\begin{abstract}
A formação profissional deverá desenvolver a capacidade de: elaborar, executar e avaliar planos, programas e projetos na área social; contribuir para viabilizar e participação dos usuários nas decisões institucionais; planejar, organizar e administrar benefícios e serviços sociais; realizar pesquisas que subsidiem a formulação de políticas e ações profissionais; prestar assessoria e consultoria a órgãos da administração pública, empresas privadas e movimentos sociais em matérias relacionadas às políticas sociais e à garantia de direitos civis, políticos e sociais da coletividade; orientar a população na identificação de recursos para atendimento e defesa de seus direitos; realizar visitas, perícias técnicas, laudos, informações e pareceres sobre matéria de Serviço Social (BRASIL, 2002, p. 401402, grifos originais).
\end{abstract}

Nessas foram subtraídas algumas competências exigidas no documento da Comissão de Especialistas, como: realizar estudos socioeconômicos para identificação de demandas e necessidades sociais; assumir o magistério de Serviço Social e coordenar cursos e unidades de ensino e supervisionar diretamente estagiários de Serviço Social. Como se verifica, houveram supressões de passagens do texto original, em consonância com as propostas pedagógicas da UNESCO, que dão direcionamento às competências e habilidades no exercício profissional do/a assistente social.

A supressão da compreensão crítica dos processos sociais na sua totalidade em detrimento de aportes instrumentalizáveis, a exemplo da introdução de recursos de informática ${ }^{3}$ e de uma formação por competência, demonstra as tentativas das figuras representativas do capital em intensificar os processos formativos das profissões aos anseios do mundo do trabalho. Especificamente no Serviço Social essas modificações tendem a limitar o exercício profissional ao caráter meramente técnico, pois como elucida lamamoto (2014): "O discurso que fundamenta a formação por competência pode encontrar na cultura profissional do Serviço Social uma ambientação favorável à sua

\footnotetext{
${ }^{3}$ Com isso não estamos afirmando que o domínio da informática no exercício profissional não seja relevante, entretanto, o conteúdo desse recurso não equivale aos conteúdos relativos à apreensão crítica dos processos sociais e históricos.
} 
difusão em decorrência de seus vínculos com a empiria e certa mitificação da 'prática profissional" (IAMAMOTO, 2014, p. 627).

São modificações que comprometem a elucidação da defesa dos princípios norteadores da formação acadêmico-profissional, visto que esses ultrapassam a mercantilização do conteúdo intelectual do trabalhador, pois estão fundadas na totalidade da vida social, dentre os quais afirma-se o "[...] rigoroso tratamento teórico, histórico e metodológico da realidade social e do Serviço Social que possibilitem a compreensão dos problemas e desafios com os quais o profissional se defronta no universo da produção e reprodução da vida social" (ABEPSS/CEDEPSS, 1997, p. 6). Assim, para lamamoto (2014), o texto das Diretrizes Curriculares, homologadas em 2001, sofre forte "[...] descaracterização no que se refere à direção social da formação profissional, aos conhecimentos e habilidades considerados essenciais ao desempenho do assistente social" (IAMAMOTO, 2014, p. 616, grifos nossos). Nessa ótica de análise, requer levantarmos algumas concepções teóricas de competências por entendermos que os estudos dos autores aqui mencionados representam além de uma contraposição à lógica do mercado, a resistência ético-política no sentido de dar qualidade às competências e ao exercício profissional.

Iniciamos com a compreensão de competência profissional salientada pela autora Marilda Vilela lamamoto. No texto "O Serviço Social na cena contemporânea", de 2009, a autora traz a discussão da competência envolvida pela dimensão crítica, denominando-a de competência crítica. Para lamamoto (2009), essa se difere do mero discurso da competência empreendida pelos aparatos dos empregadores mercadológicos. Se para esse a competência está relacionada às exigências burocráticas e administrativas que precisam ser cumpridas, traçadas por procedimentos previamente estabelecidos, regidos pela noção de eficácia e eficiência, a competência é, portanto, "[...] personificada no discurso do administrador burocrata, da autoridade fundada na hierarquia que dilui o poder sob a aparência de que não é exercido por ninguém" (IAMAMOTO, 2009, p. 17). Oposto a essa compreensão, para a autora, a competência crítica supõe uma relação intrínseca com as fontes que fundamentam o conhecimento e os pontos de vista das classes que gestam "[...] suas bases históricas, a maneira de pensar e interpretar a vida social das classes (ou segmentos de classe) que apresentam esse discurso como dotado de universalidade, identificando novas lacunas e omissões" (IAMAMOTO, 2009, p.17), a partir de uma teoria social crítica. A competência crítica supõe:

a) um diálogo crítico com a herança intelectual incorporada pelo Serviço Social e nas autorrepresentações do profissional, cuja porta de entrada para a profissão passa pela história da sociedade e pela história do pensamento social na modernidade, construindo um diálogo fértil e rigoroso entre teoria e história; b) um redimensionamento dos critérios da objetividade do conhecimento, para além daqueles promulgados pela racionalidade da burocracia e da organização, que privilegia sua conformidade com o movimento da história e da cultura. A teoria afirma-se como expressão, no campo do pensamento, da processualidade do ser social, apreendido nas suas mútuas relações e determinações, isto é, como 'concreto pensado" (MARX, 1974 apud IAMAMOTO, 2009, p. 17).

Nas ideias de lamamoto, esses elementos são necessários à compreensão de competências no interior da profissão, pois que possibilita superar a mera concepção de 
competência enquanto o saber fazer fruto da racionalidade burguesa. Em suas ideias, a competência crítica evidencia o significado social da profissão, sua função social, suas defesas políticas, a apreensão da totalidade social e dos fundamentos da ordem do capital. Para a autora, a profissão enquanto uma "[...] especialização do trabalho da sociedade, inscrita na divisão social e técnica do trabalho social" (IAMAMOTO; CARVALHO, 2007) e, portanto, atividade assalariada, está condicionada às correlações de força do capital. Nessa angulação, o projeto profissional da profissão tensiona as competências profissionais a se contrapor às exigências mercadológicas do capital. Assim, conforme lamamoto, o exercício da profissão exige um profissional que tenha competência de ir além da imediaticidade institucional para buscar apreender "[...] no movimento da realidade e na aproximação as forças vivas de nosso tempo, tendências e possibilidades aí presentes passíveis de serem apropriadas pelo profissional e transformadas em projetos de trabalho profissional" (IAMAMOTO, 2014, p. 611).

No conjunto dos textos da autora Yolanda Guerra, a discussão das competências profissionais perpassa o estudo acerca da compreensão da instrumentalidade, das demandas, requisições e respostas profissionais e da articulação com as dimensões técnico-operativa, teórico-metodológica, ético-política e investigativa. Para Guerra et al (2016):

Competência e habilidade são dois conceitos que estão relacionados. A habilidade é conseguir pôr em prática as teorias e conceitos que foram adquiridos, enquanto a competência é mais ampla e consiste na articulação entre conhecimentos, atitudes e habilidades (GUERRA et al., 2016, p. 8).

A articulação entre as dimensões do conhecimento, valores e princípios, habilidades etc., devem ser tratados numa organicidade que possibilite fundamentar as competências. A autora assevera que as dimensões da profissão não são fixas ou autônomas, pois uma existe em relação com as outras, apesar de em algumas situações se requisitem competências e/ou atribuições profissionais que haja um maior predomínio de uma sobre a outra, isso não elimina aquela relação. Apesar desse reconhecimento, a autora salienta que "[...] a dimensão técnico-operativa é a forma de aparecer da profissão, pela qual é conhecida e reconhecida" (GUERRA, 2017, p. 50). Para tanto, não é de se estranhar quando somos indagados com a pergunta: o que faz o/a assistente social? o que compete ao assistente social no seu exercício profissional? De imediato nos vem a resposta embasada pelas orientações da Lei de Regulamentação da Profissão, nas quais competências e atribuições profissionais são destacadas como: elaborar, implementar, executar e avaliar políticas sociais; elaborar, coordenar, executar e avaliar planos, programas e projetos que sejam do âmbito de atuação do Serviço Social, dentre outras. Essas, por sua vez, demonstram o caráter interventivo da profissão. Entretanto, apesar das competências profissionais de modo imediato demonstrem essa dimensão técnicooperativa, interventiva, aquela por sua vez, não é neutra.

A contenção da compreensão das competências profissionais à dimensão técnicooperativa "[...] é insuficiente para dar respostas qualificadas à realidade social [...]" (GUERRA, 2017, p. 50), além disso, pela própria natureza da profissão, se limitarmos as competências do/a assistente social à utilização de procedimentos técnico-operativos, 


\section{tempordilis queroz, Mavreat}

corremos o risco de cair na tendência criticada durante os anos 1970 - o metodologismo; no oportunismo teórico-metodológico, lançando mão de um referencial teórico eclético; e na construção de uma imagem social da profissão, incorporando uma noção equivocada de "Serviço Social como Técnica Social ou Tecnologia (conjunto de técnicas) [...]" (GUERRA, 2017, p. 71) ou de mudança comportamental destinada a solucionar problemas.

Em contraposição a esses riscos, é necessário reunir o conjunto das dimensões teóricometodológica, ético-política, formativa e investigativa, no sentido de fundamentar o fazer profissional, pois ainda que apareça de modo imediato na capacidade técnica de resolução de problemáticas, essa competência é carregada a partir de um conjunto de forças teórica, ética, saberes práticos e interventivos, etc. É, portanto, nesse sentido que a autora denomina as competências como socioprofissionais e políticas.

Ao analisarmos textos da autora Rosa Lúcia Prédes Trindade, defende-se que o Serviço Social ocupa um "[...] espaço na divisão social e técnica do trabalho, ao lado de outras profissões, participando da tarefa de implementação de condições necessárias ao processo de reprodução social" (TRINDADE, 2001, p. 2). A partir dessa ideia, a autora faz uma análise acerca das particularidades do instrumental técnico-operativo do Serviço Social, embora no texto não realize uma discussão direta acerca da concepção de competências profissionais, compreendemos que o estudo dos determinantes sóciohistórico do instrumental técnico-operativo perpassa o entendimento de que a profissão é possuidora de uma competência interventiva e, portanto, nesse processo de intervenção acionam-se um conjunto de instrumentos e técnicas, os quais são utilizados como mediação e potencializadores no processo interventivo às demandas postas à profissão (TRINDADE, 2001).

Entendemos a partir da autora, que o profissional é requisitado a responder às demandas postas pelas classes sociais, ora pela própria exigência de quem lhe contrata, ora porque a profissão detém competências que Ihe são próprias, enquanto parte constitutiva do significado social da profissão. Tais competências não se limitam ao aspecto técnico interventivo, pois as ações profissionais estão permeadas pelas concepções teóricas, ético e política que ao longo da história da profissão foram dialeticamente construídas e reconstruídas. Resultado desse processo é a defesa do Projeto Ético Político da Profissão. Apreendemos no estudo da autora que as competências profissionais são parte constitutiva da profissão, as quais não se reduzem ao aspecto técnico-operativo em sua postura interventiva. As competências, por sua vez, acionam um conjunto de mediações construídas historicamente ao longo do processo acumulativo de conhecimento teórico, prático e político da profissão.

Concluímos que as considerações dos intelectuais aqui analisados, que desempenham seus estudos e pesquisas sobre os Fundamentos do Serviço Social e, portanto, atravessam o campo das competências, são adversas das concepções apontadas pela Sociologia do trabalho a partir de Zarifian, bem como das orientações dos organismos internacionais, bem como do MEC. Conforme se notou em linhas atrás, a defesa da formação por competência mediante essas representações centra-se em um modelo de formação a partir dos conhecimentos, das habilidades, dos comportamentos e dos 
atributos subjetivos dos indivíduos, estimulando esses elementos na organização das disciplinas para o desenvolvimento de competências que são estruturadas para um perfil de profissional estabelecido previamente pelo mercado de trabalho, além disso, desloca a centralidade do conhecimento de caráter teórico para conteúdos de caráter meramente instrumentalizável.

A nosso ver, a defesa dessa formação por competência intensificada pela lógica do capital, traz inúmeras implicações para a formação em Serviço Social, das quais destacamos: 1) As competências tenderão a ser reduzidas à compreensão da dimensão técnico-operativa, a partir de um padrão de conhecimento instrumentalizável, destituído do acervo teórico crítico; 2) As competências profissionais tenderão a responder meramente às requisições mercadológicas, abstraindo os objetivos e defesas coerentes com o Projeto Ético Político Profissional; 3) Em simetria com as duas anteriores, corremos o risco da retomada de um perfil de profissional tecnicista, e mais, em uma formação ainda eminentemente feminina, corremos o risco de uma possível retomada ao estereótipo da "bondade feminina", atrelada às "habilidades de mudanças de comportamentos", de desenvolvimento de "ações de ajuda", dentre outras.

Portanto, abordar a compreensão das competências profissionais no Serviço Social a partir do modelo por competências, essas por sua vez, definidas em aportes técnicos e na subjetividade dos sujeitos, a nosso ver é assegurar ao mercado um perfil de profissional instruído à lógica da racionalidade burguesa. É preciso, portanto, que na construção das competências volte-se aos caminhos percorridos pelo Serviço Social no Brasil e na América Latina, que romperam com uma visão endógena da profissão e tensionaram a superação de posturas conservadoras tanto na teoria como na prática profissional. Nessa viagem, capturar os avanços e acúmulos teóricos assentados na perspectiva marxista, políticos, metodológicos e éticos, norteiam os valores e princípios éticos que embasam a formação das competências profissionais.

\section{CONCLUSÃO}

Chegamos à conclusão de que apesar da existência de documentos que, a exemplo da Lei de Regulamentação/1993 e do Código de Ética/1993, definem quais as ações se configuram como competências e atribuições profissionais do/a assistente social, não há uma concepção engessada do conceito de competências no Serviço Social. Nestes documentos, fica claro que a competência profissional é expressão de uma leitura histórico-crítica. Isso significa dizer que quando se trata de competências profissionais, os estudos na área demonstram o resgate do significado social da profissão.

Competências profissionais no Serviço Social são, portanto, um constructo histórico da profissão, não é apenas a definição do que faz o/a assistente social, como: elaborar, executar, implementar planos, programas, etc., mas também, demonstrar seu significado sócio-histórico no âmbito da divisão sócio técnica do trabalho. Embora o Código de Ética da Profissão apresente as competências profissionais como algo não exclusivo da profissão, por sua vez, estão associadas aos conteúdos intrínsecos à profissão e aos 


\section{tempordils \\ QUEIROZ, MAYRA DE}

elementos com os quais a profissão atua: os sujeitos sociais, as políticas sociais, o Estado, as demandas, os direitos sociais, a ordem capitalista, etc. Portanto, esse teor diferencia e legitima a competência profissional do/a assistente social, não confundido-o com outros profissionais.

À guisa da conclusão, essa compreensão vai na contramão das ideias de formação por competências defendida e difundida pelos organismos internacionais. A nosso ver, a reconfiguração do ensino superior por competência traz impactos às profissões que historicamente construíram suas defesas assentadas não em uma formação profissional que atendesse apenas aos asseios do mercado de trabalho, mas também, que essa mesma formação vise um compromisso ético, político e teórico com a classe trabalhadora. Ora, nesse sentido, competências não são apenas o que fazer, é também questionar-se: por que fazer? para que fazer? como fazer? As repostas a essas perguntas perpassam as dimensões destacadas pelos autores que investigam o Serviço Social. Concluímos afirmando a competência profissional é resultado sócio-histórico da profissão, do processo dialético de construção e reconstrução dos processos históricos que permitiram o amadurecimento da profissão de Serviço Social.

\section{REFERÊNCIAS}

ABEPSS/CEDEPSS. Diretrizes Gerais para o curso de serviço social (com base no currículo mínimo aprovado em assembleia geral extraordinária de 8 de novembro de 1996).

Cadernos Abess, São Paulo, n. 7, p.58-76, 1997.

BOLIVAR, Antônio. O Planejamento por competência na reforma de Bolonha da Educação Superior: uma análise crítica. In: PEREIRA, Elisabeth Monteiro de Aguiar; ALMEIDA, Maria de Lourdes Pinto de (org.). Universidade contemporânea: políticas do processo de Bolonha. São Paulo: Mercado de Letras, 2009.

BRASIL. Lei n 9.394, de 20 de dezembro de 1996. Estabelece as Diretrizes e Bases da Educação Nacional. Diário oficial da União. Brasília, DF, 23 dez. 1996. Disponível em: http://www.planalto.gov.br/CCIVIL_03/leis/L9394.htm. Acesso em: 23 set. 2018.

BRASIL. Ministério da Educação. Parecer 776/97, de 03 de dezembro de 1997. Orientação para as diretrizes curriculares dos cursos de graduação. Brasília, DF, 03 dez. $1997 a$. Disponível em: http://portal.mec.gov.br/setec/arquivos/pdf_legislacao/superior/legisla_superior_parecer 77697.pdf. Acesso em: 23 set. 2018.

BRASIL. Ministério da Educação. Parecer CNE/CEB n¹6/99. Trata das Diretrizes Curriculares Nacionais para a Educação Profissional de Nível Técnico. Brasília, DF, 5 out. 1999a. Disponível em: http://portal.mec.gov.br/setec/arquivos/pdf/PCNE_CEB16_99.pdf. Acesso em: 23 set. 2018. 


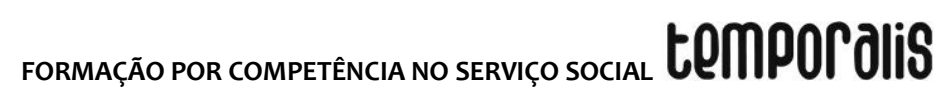

BRASIL. Ministério da Educação. Edital nº 04/97, de 10 de dezembro de 1997. Convoca as Instituições de Ensino Superior a apresentar propostas para as novas Diretrizes Curriculares dos cursos superiores, que serão elaboradas pelas Comissões de Especialistas da Sesu/MEC. Brasília, DF, 10 dez. 1997b. Disponível em: http://portal.mec.gov.br/sesu/arquivos/pdf/e04.pdf. Acesso em: 23 set. 2018.

BRASIL. Ministério da Educação. Resolução CNE/CEB n04/99, de 08 de dezembro de 1999b. Institui as Diretrizes Curriculares Nacionais para a Educação Profissional de Nível Técnico. Brasília, DF, 04 dez. 1999. Disponível em: http://portal.mec.gov.br/setec/arquivos/pdf/RCNE_CEB04_99.pdf. Acesso em: 11 out. 2018.

BRASIL. Ministério da Educação. Resolução CNE/CES 15, de 13 de março de 2002. Estabelece as Diretrizes Curriculares para os cursos de Serviço Social. Conselho Nacional de Educação, Brasília, 2002. Disponível em:

http://portal.mec.gov.br/cne/arquivos/pdf/CES152002.pdf. Acesso 11 out. 2018.

BRASIL. Ministério da Educação. Parecer CNE/CES 492/2001 de 03/04/2001. Diretrizes Curriculares Nacionais dos cursos de Filosofia, História, Geografia, Serviço Social, Comunicação Social, Ciências Sociais, Letras, Biblioteconomia, Arquivologia e Museologia. Ministério de Educação/Conselho Nacional de Educação, Brasília, DF, 2001a. Disponível em http://portal.mec.gov.br/cne/arquivos/pdf/CES0492.pdf. Acesso em: Acesso 11 out. 2018.

BRASIL. Ministério da Educação. Parecer CNE/CES 583/2001 de 04 de abril de 2001. Orientação para as diretrizes curriculares dos cursos de graduação. Ministério da Educação/ Conselho Nacional de Educação. 4 de abril de 2001b. Disponível em: http://portal.mec.gov.br/cne/arquivos/pdf/CES0583.pdf. Acesso 11 out. 2018.

BRUNO, L. Educação e desenvolvimento econômico no Brasil. Revista Brasileira de Educação, São Paulo, v. 16, n. 48, 2011. Disponível em: http://www.scielo.br/pdf/rbedu/v16n48/v16n48a02.pdf. Acesso em: 21 out. 2018.

DELORS, J. Educação: um tesouro a descobrir. 10. ed. São Paulo: Cortez e MEC/ UNESCO, 1998. Disponível em: http://www.dominiopublico.gov.br/download/texto/ue000009.pdf. Acesso em: 21 set. 2018.

GUERRA, Yolanda. A instrumentalidade no trabalho do assistente social. In: SIMPÓSIO MINEIRO DE ASSISTENTES SOCIAIS, Belo Horizonte. Anais [...]. Belo Horizonte: CRESS, maio 2007. Disponível em:

http://unesav.com.br/ckfinder/userfiles/files/Yolanda\%20Guerra\%2oinstrumentalid.pdf. Acesso em: 23 out. 2018.

GUERRA, Yolanda. A dimensão técnico-operativa do exercício profissional. In: SANTOS, Cláudia Mônica dos; BACKX, Sheila de Souza. A dimensão técnico-operativa no Serviço Social: desafios contemporâneos. 3. ed. São Paulo: Cortez, 2017. 


\section{tempordils \\ Queror, Mara 0 E}

GUERRA, Yolanda. et al. Atribuições, competências, demandas e requisições: o trabalho do assistente social em debate. In: ENCONTRO NACIONAL DE PESQUISADORES EM SERVIÇO SOCIAL, 15., Ribeirão Preto. Anais [...]. Ribeirão Preto: ENPESS, 2016. Disponível em: http://www.abepss.org.br/arquivos/anexos/guerra-e-outros201804131237474299190.pdf. Acesso em: 25 nov. 2018.

IAMAMOTO, M. Projeto profissional, espaços ocupacionais e trabalho do(a) assistente social na atualidade. In: CFESS. Atribuições privativas do/a assistente social em questão. 1. ed. aum. Brasília: CFESS, 2012. Disponível em: http://www.cfess.org.br/arquivos/atribuicoes2012-completo.pdf. Acesso em: 05 out. 2018.

IAMAMOTO, M. O serviço social na cena contemporânea. In: CFESS. Serviço Social: direitos sociais e competências profissionais. Brasília: CFESS/ABEPSS. 2009.

IAMAMOTO, M. A formação acadêmico-profissional no Serviço Social brasileiro. Revista Serviço Social e Sociedade, São Paulo, n. 120, 2014.

IAMAMOTO, M. 80 anos do Serviço Social no Brasil: a certeza na frente, a história na mão. Revista Serviço Social e Sociedade, São Paulo, n. 128, 2017.

IAMAMOTO, M.; CARVALHO, R. Relações sociais e serviço social no Brasil. São Paulo: Cortez; Celats, 2007.

MACHADO, L. A institucionalização da lógica das competências no Brasil. Pro-Posições, São Paulo, v. 13, n. 1, 2002. Disponível em: https://www.fe.unicamp.br/pffe/publicacao/2128/37-dossie-machadol.pdf. Acesso em: 08 nov. 2015.

MÉSZÁROS, István. Para além do capital: rumo a uma teoria da transição. Trad. Paulo César Castanheira e Sérgio Lessa. São Paulo: Editora da Unicamp/Boitempo Editorial, 2002.

NETTO, José Paulo. Capitalismo monopolista e serviço social. 8. ed. São Paulo: Cortez, 2011.

TRINDADE, Rosa Lúcia Prédes. Desvendando as determinações sócio-históricas do instrumental técnico-operativo do serviço social na articulação entre demandas sociais e projetos profissionais. Revista Temporalis, n. 04. Brasília, DF: CFESS/ABEPSS. 2001.

TRINDADE, Rosa Lúcia Prédes. Ações profissionais, procedimentos e instrumentos no trabalho dos assistentes sociais nas políticas sociais. In: SANTOS, Cláudia Mônica dos; BACKX, Sheila de Souza. A dimensão técnico-operativa no serviço social: desafios contemporâneos. 3. ed. São Paulo: Cortez, 2017.

RAMOS, M. A pedagogia das competências: autonomia ou adaptação?. 2. ed. São Paulo: Cortez, 2002. 
SANTOS, Leila Lima. Metodologismo: explosão de uma época. In: . Textos de

Serviço Social. 4. ed. São Paulo: Cortez, 1987.

TUNING AMÉRICA LATINA. Reflexões e perspectivas do Ensino Superior na América Latina: relatório final - proyecto Tuning - América Latina 2004-2007. Deusto [Espanha]: Universidade de Deusto; Groningen [Holanda]: Universidade de Groningen, 2007. Disponível em: http://tuningacademy.org/wp-content/uploads/2014/02/TuningLAIII_FinalReport_PT.pdf. Acesso em 09 set. de 2018.

UNESCO. Declaração Mundial sobre Educação Superior no século XXI: Visão e Ação. Paris: UNESCO, 9 out. 1998. Disponível em: http://www.direitoshumanos.usp.br/index.php/Direito-aEduca\%C3\%A7\%C3\%A30/declaracao-mundial-sobre-educacao-superior-no-seculo-xxi-visaoe-acao.html. Acesso em: 20 jun. 2015.

WERNER, Rosiléia Clara. Desafios contemporâneos na formação profissional: o desenvolvimento de competências e habilidades no Serviço Social. Tese (Doutorado em Serviço Social) - Pontifícia Universidade Católica de São Paulo, São Paulo, 2010.

ZARIFIAN, P. Objetivo competência, por uma nova lógica. São Paulo: Atlas, 2001.

ZARIFIAN, P. O modelo da competência: trajetória histórica, desafios atuais e propostas. São Paulo: Editora Senac, 2003.

\footnotetext{
Mayra de QUEIROZ

Bacharel em Serviço Social pela Universidade Federal de Alagoas. Mestra em Serviço Social pelo Programa de Pós-graduação em Serviço Social da Universidade Federal de Alagoas. Doutoranda do Programa de Pós Graduação em Serviço Social da Faculdade de Serviço Socia/UFAL. Tem experiência na área de Serviço Social, com ênfase em Fundamentos do Serviço Social, atuando principalmente nos seguintes temas: Serviço Social; demandas sociais; trabalho e educação, questão social, política social, mercado de trabalho do Serviço Social. Docente do Curso de Serviço Social, na Universidade Federal de Alagoas-Unidade Palmeira dos Índios.
} 